\title{
(RE)CONSTRUINDO-SE PROFESSOR REFLEXIVO: UMA ANÁLISE BIBLIOGRÁFICA
}

\author{
Glessiane Coeli Freitas Batista Prata ${ }^{1}$
}

\section{RESUMO}

Este artigo se trata de um estudo sobre professor reflexivo e as dificuldades de se adquirir uma postura reflexiva diante dessa tendência tradicional. Temos por objetivo levantar questionamentos sobre essa teoria, como elas são incorporadas pelos os docentes, se há uma reflexão sobre a abordagem ou se eles se deixam levar pelo "modismo" que deformam o real conceito da teoria. Também, é válido discutir e questionar os entraves que os professores enfrentam para adquirir novas posturas, levando em consideração o predominio da tendência tradicional. Foi realizado a metodologia do tipo estudo bibliográfico na produção deste artigo, levando em conta os autores Schon, Pérez Gomez, Tardif, Zeichner, Pimenta e Contreras sobre o tema formação de professores. Diante do que foi visto, percebemos que o professor encontra situações propícias para o desenvolvimento de uma postura reprodutiva no seio de sua formação. No entanto, não se pode acreditar que uma teoria ou outra irá mudar radicalmente a educação, que a partir de tal teoria se estará formando homens conscientes, críticos em seu contexto. Mesmo porque a Educação Tradicional ainda prevalece com o preceito de "vaga na universidade". Concluimos que é necessária uma reflexão crítica sobre as teorias que surgem na área de formação docente e, também levantar questionamentos para investigações posteriores como: qual formação nos queremos? Se é suficiente conceber essas novas teorias como se fossem pacotes de instrução de como fazer? Por isso precisamos mais do que novas teorias. É preciso uma reflexão mais profunda e uma ação mais efetiva.

Palavras Chave: Identidade Docente, Formação Docente, Professor Reflexivo

\section{ABSTRACT}

This paper reports a study about reflexive teacher and the troubles to adquire a reflexive attitude in front of the traditional trend. Inquiry this theory, about how it is built in teachers, if there is a reflection above the approach or if they let take by "modism" that deform the real concept of theory. Considering the predominance of the traditional trend, it is valid discuss and question clogs that professors meet to adquire new attitudes. Methods: It was performed a bibliographic study about the authors: Schon, Pérez Gomez, Tardif, Zeichner, Pimenta and Contreras within the theme teacher formation. Results: We perceive that the professor finds propitious situations for the development of a reproductive position in the birth of its formation. However, it cannot believe that a theory or another one will go to radically change the education, that such theory will be forming conscientious men, critical in their context. Even because the Traditional Education still prevails with the "position in the university". We conclude that is necessary a critical reflection on the theories that appear in the area of teaching formation and questions for posterior inquiries like: what formation do we want? Is it enough to conceive these new theories as if they were packages of instructions? Therefore we need more than new theories. It is necessary a deeper reflection and an more effective action.

Key Words: Teaching Identity, Teacher Formation, Reflexive Teacher

\footnotetext{
${ }^{1}$ Docente da Faculdade Tecnológica Apoena - FTA. glessiane@hotmail.com ISSN 1983-1579 


\section{INTRODUÇÃO}

Diante das mudanças que vem ocorrendo no mundo do trabalho, no qual se exige mãode-obra qualificada, índices crescentes na produção, ao mesmo tempo o sistema não permite mais que isso, uma formação puramente técnica, sem nenhuma conscientização crítica, pessoas pensantes sobre os problemas que os permeiam. Essa é a lógica do capital em relação à formação escolar (MARCHESI, 2003).

Seguindo essa lógica o papel do professor seria então formar pessoas centradas no mercado de trabalho? E ficariam a cargo de quem a formarção de alunos com consciência política, cultural e humana além da transmição de valores éticos, morais e da construção de conhecimento crítico de acordo com a realidade do aluno? Cabe questionar que vies a formação docente está tomando.

Há muito tempo se vem culpabilizando o professor os fracassos escolares, a má formação dos alunos, a falta de compromisso com a profissão. Antes de se fazer julgamentos temos que analisar a situação que esse profissional se encontra, pois ele, assim como os alunos é um fantoche do sistema, por isso é importante questionar como se está realizando a formação docente, o trabalho docente e a influencia dessa cultura escolar no trabalho realizado por ele.

Nesse artigo iremos discutir sobre a formação do professor reflexivo, que apesar de ser um tema bastante atual, surgiu na década de 1970 com Donald Schõn, influenciado por John Dewey. Assim como ele, Schõn tem como idéia principal em sua teoria, a importância de se entrelaçar a relação entre teoria e prática, ou seja, os conhecimentos teóricos devem ser aplicados aos acontecimentos do cotídiano.

Zeichner (1993) e Contreras (2002) teorizam o professor reflexivo de maneira mais abrangente, na qual essa reflexão não é uma atividade individual, pois pressupõe relações sociais que servem a interesses humanos, sociais, culturais e políticos e, dessa forma, não é neutra.

Temos por objetivo levantar questionamentos sobre essa teoria; discutir como elas são incorporadas pelos docentes; se há uma reflexão sobre a abordagem ou se eles se deixam levar pelo modismo que deformam o real conceito da teoria. Também, é valido discutir e questionar os entraves que os professores enfrentam para adquirir novas posturas didáticas, levando em consideração a influência da tendência tradicional.

A metodologia realizada na produção deste artigo foi do tipo estudo bibliográfico, realizamos um levantamento bibliográfico, utilizando a base de dados da Universidade Estadual do Ceará - UECE e Universidade Federal do Ceará UFC, onde buscamos os principais autores que referendavam sobre o tema pertinente, os autores escolhido foram: Schon (2000, 2002), Pérez Gomez (1992), Tardif (2002), Zeichner (1992, 1993), Pimenta (2002) e Contreras (2002), Após coletar todos os textos realizamos leituras e fichamentos sobre os temas relacionados a formação de professores.

\section{AS CONTRIBUIÇÕES CONCEITUAIS DE J. DEWEY E DE D. SCHÕN PARA A TEORIA DO PROFESSOR REFLEXIVO}

Levando-se em conta o conceito de pensar, o que é o pensar ? Genericamente o ato de pensar é tácito, ninguém o ensina como se deve pensar. Porém podem ser indicadas e descritas em seus aspectos gerais, há várias maneiras de se pensar, para Dewey (1959) a melhor maneira é chamada pensamento reflexivo, consiste em examinar mentalmente o assunto e dar-lhe considerações sérias e consecutivas. 
O que diferencia o homem dos animais inferiores é a capacidade de pensar, por isso é importante o pensar reflexivo, que nos dá capacidade para o emancipar da ação unicamente impulsiva, rotineira. Ele nos torna capazes de dirigir, conscientemente, nossas atividades com previsão e de planejar de acordo com um objetivo a ser alcançado. Traz à mente possibilidades de ação diante do imprevisível, enfim converte uma ação puramente mecânica, cega e impulsiva, em ação inteligente. Em outras palavras, a pessoa deixa de ser um ser passivo, acrítico a um ser mais ativo, crítico do que acontece ao seu redor. (DEWEY, 1959)

O pensamento reflexivo se dá em cadeia, pois consiste em uma sucessão de coisas pensadas, não em sequência, mas uma conseqüência, da maneira que cada idéia gera outra, naturalmente, e ao mesmo tempo se apóia na antecessora. É um movimento de idas e vindas. Por isso se deve levar em consideração a experiência de cada um, pois esse movimento reflexivo depende da vivência do indivíduo, de poder pensar sobre o que aconteceu, o que acontece e o que poderá acontecer.

Não temos como falar de pensamento reflexivo sem falar de experiência. Para Dewey ( op.cit.), todo conhecimento autêntico procede da experiência, mas a experiência, para ele, não é uma simples recepção passiva de uma grande quantidade de impressões. A experiência é, ao contrário, uma operação ativa, inicialmente uma resposta do organismo e depois da personalidade e da inteligência, às solicitações do meio. A ação sobre outro corpo e a reação sofrida nesse processo é o que pode ser chamado de experiência.

Tendo o conceito de experiência como fator central de seus pressupostos, chega à conclusão de que a "escola não pode ser uma preparação para a vida, mas sim, a própria vida" (DEWEY, 1978: 37). Assim, para ele, vida, experiêncía e aprendizagem estão unidas, de tal forma que a função da escola encontra-se em possibilitar uma reconstrução permanente pela experiência da criança. "Afínal, as crianças não estão, num dado momento, sendo preparadas para a vida e, em outro, vivendo"(Dewey, op. Cit. p.17), ensinou, argumentando que o aprendizado se dá justamente quando os alunos são colocados diante de problemas reais. A educação, na visão de Dewey (op. Cit. p.17), é "uma constante reconstrução da experiência, de forma a dar-lhe cada vez mais sentido e a habilitar as novas gerações a responder aos desafios da sociedade". Educar, portanto, é mais do que reproduzir conhecimentos. É incentivar o desejo de desenvolvimento contínuo, preparar pessoas para transformar algo.

A experiência educativa é, na verdade, uma experiência reflexiva; um aprender fazendo, que resulta em novos conhecimentos. Deve seguir alguns pontos essenciais: que o aluno esteja numa verdadeira situação de experimentação; que a atividade o interesse; que haja um problema a resolver; que ele possua os conhecimentos para agir diante da situação e que tenha a chance de testar suas idéias.

Diante desses conceitos que influenciaram fortemente Schõn(1992), foi que surgiu a teoria do professor reflexivo. No decorrer do texto abaixo perceberemos facilmente a apropriação dessas idéias, como também, bastante semelhança com os estudos de Paulo Freire. No entanto, em nenhuma obra escrita por Schõn ele o referencia.

\section{O QUE É SER PROFESSOR REFLEXIVO?}

Nas últimas décadas, podemos perceber algumas mudanças que ocorreram no mundo do trabalho pela globalização, pelas inovações tecnológicas e pela reestruturação produtiva, causando um impacto no perfil do trabalhador, e consequentemente a necessidade de mudança dos processos formativos. Esses processos se espelham no paradigma taylorista baseado na racionalidade técnica, concebendo o exercício profissional como atividade meramente instrumental que aplica teorias, métodos e técnicas para a solução de problemas. 
Nesse âmbito capitalista, a escola sofre mudanças a fim de se adequar às novas exigências do mercado de trabalho. Sendo assim, o modelo ideal de educação escolar, que tem por funções formar alunos com consciência política, cultural e humana além de transmitir valores éticos, morais e na construção de conhecimento crítico de acordo com a realidade do aluno, perde importância devido à necessidade mercadológica de rnão-de-obra técnica.

É diante desse contexto que precisamos fazer uma reflexão para saber como está sendo realizada a formação docente. Que professores estamos formando? E que alunos, esses professores, estão educando? E como estão educando? Qual o papel desse homem na sociedade? Vários questionamentos surgem, no entanto focalizaremos a formação docente mais especificamente no que se refere à teoria do professor reflexivo.

No Brasil, a formação de professores ganhou força com a chegada de algumas teorias como professor reflexivo, crítico e pesquisador. A difusão do conceito de professor reflexivo no Brasil aconteceu no início dos anos 1990, com a divulgação do livro "Os professores e sua formação", coordenado pelo professor português António Nóvoa, e com a participação de um grupo de pesquisadores brasileiros no I Congresso sobre Formação de Professores nos Países de Língua e Expressão portuguesas, realizado em Aveiro - Portugal, 1993, sob a coordenação da professora Isabel Alarcão.

Depois desses acontecimentos, a vinda desses dois portugueses ao Brasil virou uma constante, pois foram convidados por escolas e universidades para palestrar sobre tal tema. Como se sabe, no Brasil, as teorias parecem modismo, pois sempre há uma efervescência a cada teoria que surge.

Conforme frisamos, a idéia de professor reflexivo surge com Donald Schõn, professor de estudos urbanos e de educação no MIT (Massachusetts Institute of Tchnology), com formação filosófica de base e influenciado por John Dewey. Schõn faz uma crítica à racionalidade técnica que antecede a teoria do profissional reflexivo.

A racionalidade técnica é uma concepção da prática, herdada do positivismo, intrínseca ao modelo taylorista, que prevaleceu ao longo de todo o século $\mathrm{XX}$, servindo de referência para a educação e a socialização dos profissionais em geral e dos docentes em particular (Pérez Gómez, 1992).

Schõn (1992) faz crítica à racionalidade técnica, à incapacidade deste método em lidar com o imprevisível; mostra como as regras técnicas não são capazes de resolver problemas que estão fora do seu repertório teórico; e quando essas respostas se esgotam, o profissional não sabe como lidar com a situação-problema.

É diante desse contexto que surge a ideia do profissional reflexivo, o qual busca solucionar problemas, as quais não foram encontradas respostas, devido à limitação da racionalidade técnica diante do inesperado.

Observando a prática de profissionais, Schõn (2000) critica o currículo normativo, propondo que a formação dos profissionais não obedeça mais a esse currículo, pois o mesmo apresenta primeiramente a ciência, depois a sua aplicação e, por último, um estágio que supõe a aplicação dos conhecimentos técnicos-profissionais pelos alunos.

Schõn (2000) conclui que os profissionais que são formados de acordo com esse currículo normativo não conseguem dar respostas aos problemas que surgem no cotidiano profissional, pois essas respostas estão além dos conhecimentos elaborados pela ciência, 0 professor não deve ser o especialista que aplica conhecimentos, mas um "prático reflexivo", alguém que age e toma decisões a partir da avaliação dos problemas que surgem no decorrer do seu trabalho em sala de aula.

O autor referido realizou esta pesquisa com o intuito de avaliar o currículo dos 
profissionais em geral; não foi direcionada especificamente a formação do professor, não teve por objetivo elaborar um processo de mudança institucional e social, mas somente se focou nas práticas individuais, por isso atribuíram-se várias criticas ao seu trabalho.

Uma das criticas é feita por Zeichner (1993), quando afirma que Schon (op. Cit.), na sua teoria, trabalha a reflexão individual, que para ele é limitante, reducionista, e que empobrece o professor em termos de conhecimento, troca de saberes, críticas construtivas, a qual através dessa crítica o professor perceba suas falhas.

Zeichner (ibidem) pensa numa prática reflexiva coletiva, de cunho mais social, na qual os professores possam em grupo trabalhar as suas reflexões, suas práticas, seus saberes e assim perceberem juntamente com seus colegas seus erros e seus acertos, ou seja, dialeticamente trabalhar e enriquecer seus conhecimentos. Dessa forma mais abrangente, faz com que o grupo possa atuar juntamente à escola, à comunidade e à sociedade, agindo assim de uma forma transformadora na estrutural social

As reflexões feitas por Contreras (2002), acerca da concepção do professor reflexivo ensinam-nos que um profissional que reflete na ação deverá refletir também sobre a estrutura organizacional, sobre os pressupostos, os valores e as condições de trabalho docente. Deverá compreender como o modo de organização e controle do trabalho do professor interfere na prática educativa e na sua autonomia profissional. Assim, a reflexão não encerra uma concepção sobre si mesma, nem tem seu uso adaptável a qualquer corrente pedagógica. A reflexão guarda estreita vinculação com pensamento e ação, nas situações reais e históricas nas quais os professores se encontram. Não é uma atividade individual, pois pressupõe relações sociais que servem a interesses humanos, sociais, culturais e políticos e, dessa forma, não é neutra.

Zeichner (1992) defende a idéia do professor reflexivo que na sua prática leva em consideração o contexto social, trabalhando os conteúdos transmitidos, as situações-limite de acordo com a realidade da escola. Este professor deve buscar trabalhar de uma forma democrática e emancipatória, questionando as injustiças e desigualdades que há em sala de aula, e assim transformando o contexto escolar.

Enfim, ele acredita na reconstrução social, numa sociedade mais justa, e que isso é possível quando se trabalha conjuntamente com a escola, e na formação desses professores.

Para Contreras já citado, reflexão não é um processo puramente criativo para a elaboração de ideias, é uma prática que expressa o poder de reconstruir a vida social e, sendo vista a partir dos condicionantes que determinam os contextos sociais dos docentes, exige uma opção. Não se trata apenas de desenvolver a prática reflexiva, mas compreender a base das relações sociais e de trabalho em que ela se realiza e a que interesse ela poderá servir. É preciso que a reflexão esteja a serviço da emancipação e da autonomia profissional do professorado. Diferentemente do individualismo competitivo, ela pode ser um processo de democratização da educação, com o objetivo de construir a autonomia profissional junto com a autonomia social.

\section{O PROCESSO DE CONSTRUÇÃO DA IDENTIDADE DOCENTE NUMA VISÃO REFLEXIVA}

Durante a graduação, todos os conhecimentos adquiridos nas disciplinas de Sociologia, Filosofia, Psicologia, Didática, Metodologia dentre outras nos tornam teoricamente capacitados para exercer o magistério, no entanto, essa teoria não é o bastante para se construir a prática docente na perspectiva da ação refletida e transformadora; é preciso aprender com as experiências já vividas, com os problemas surpresa do cotidiano, ou seja, é necessário vincular teoria e prática (DEWEY, 1959). 
Teoria e prática são indissociáveis, é a teoria que explica a prática, de acordo com VAZQUEZ (1977). Nesta ótica é descartado o pragmatismo que se vincula tão somente à utilidade e que aponta como critério da verdade o êxito da açao prática do homem enquanto indivíduo.

Falar de profissão docente, da sua formação, é extrapolar os limites da teoria, é considerar todas as experiências do profissional, inclusive as que ele teve antes da graduação. Em sua vida escolar, mesmo como aluno, essa vivência influencia no seu processo de construção docente. Podemos afirmar isso quando TARDIF (2002) diz que :

Em suma, tudo leva a crer que os saberes adquiridos durante a trajetória pré-profissional, isto é, quando da socialização primária e, sobretudo quando da socialização escolar, tem um peso importante na compreensão da natureza dos saberes, do saber-fazer e do saber-ser que serão mobilizados e utilizados em seguida quando da socialização profissional e no próprio exercido do magistério. Desta forma, pode-se dizer que uma parte importante da competência profissional dos professores tem raízes em sua historia de vida, (...) (p.69).

O fazer docente profissional não é algo que acontece de uma forma isolada, apenas na formação a nível de graduação, absorvendo teorias e mais teorias, sem fazer uma relação com a prática, é todo um conjunto. O professor não é o único responsável pela sua formação, ele sofre interferências, como formação escolar, formação acadêmica, do processo educativo em geral e da sociedade como um todo. Ressalta PIMENTA (2002), que:

A formação do professor é algo muito sério. Requer investimento pessoal, institucional, público, político e social. Todos são fundamentais para a constituição do que denomino identidade epistemolôgica do professor. (p.15.)

Para os professores toma-se difícil construir-se um professor que não seja de tendência tradicional, pois se fizermos um feedback da sua vida, identificamos que ele foi vítima dos determinantes de um sistema que não lhe proporcionou outra opção se não o ensino tradicional.

Ao refletirmos sobre tais questões, podemos constatar que uma grande parte dos professores que tivemos em nossa vida escolar exerceram influência de cunho tradicionalista, ou até mesmo em relação ao acesso ao ensino superior, quando fomos levados a decorar fórmulas, conceitos, sem questionar, qual a importância daquela matéria para o nosso cotidiano; o importante mesmo era não esquecer esse conteúdo até o dia da prova, um modo bem tradicional de enfrentar os processos de avaliação.

Na universidade percebemos que isso não muda muito; o que encontramos são professores desmotivados, outros apenas com o discurso da teoria de educação libertadora, crítica, mas que, na prática, não expressa o compromisso com a turma, ao que parece, utilizam-se desse discurso para "enrolar aula". E tudo volta ao tradicionalismo; a universidade, ao invés de ser local de produção, de pesquisa, acaba se tomando um lugar de reprodução, e quando vamos exercer a profissão, com entusiasmo, com a ilusão de que vamos influir na mudança dessa realidade, enfim, vamos quebrar essa corrente tradicional, ledo engano, nossos planos são utópicos, e mais uma vez esbarramos em outra barreira.

Dessa feita, na filosofia da escola na qual trabalharemos, que apenas prima, pela 
transmissão de informações, não há um espaço para que os alunos possam questionar criticamente, pensar, sentir, atuar livremente. Assim, assume características de escola que trabalha objetivando alcançar resultados quantitativos e não qualitativos, e isso faz com que priorize a perspectiva conteudística, ou seja, algo bem técnico, repassando apenas aqueles conteúdos que eleja como importante para que o aluno desenvolva isso ou aquilo que ela tenha como finalidade, esquecendo da necessária contextualização do conhecimento. Reforça Pimenta (op. Cit.) as diferentes formas de se adquirir conhecimento:

\begin{abstract}
Ao acentuar a importância do conhecimento nas escolas, entendo que é preciso afirmar as diferentes formas pelas quais o ser humano conhece: conhecemos com as teorias, com o conhecimento elaborado, com a experiência. Mas também conhecemos por meio das emoções, do olhar instrumentalizado, da sensibilidade, da cognição, do afeto. Conhecer é um ato que mobiliza o ser humano por inteiro. ( p. 35)
\end{abstract}

Diante de tudo isso, dessas interferências, fica difícil a formação de um professor que não sofra influências marcantes de uma formação tradicional. No entanto essa mentalidade aos poucos está mudando, devido às transformações nas relações de trabalho e emprego, à nova demanda apresentada pela sociedade às escolas e professores, que exigem a atualização e cursos de formação contínua. O capital está exigindo, para sua reprodução, novas qualificações do trabalhador.

Podemos perceber o número crescente de curso de Especializações que são criados a cada semestre nas universidades, faculdades. Vale ressaltar que essa formação, apesar de ser ofertada por universidade pública, é de responsabilidade do aluno financiar cursos caros. Em parte, também é do interesse da instituição na qual ele trabalha, que ele se atualize, no entanto, a mesma não se propõe a financiar o curso.

\title{
CONSIDERAÇÕES FINAIS
}

Nas discussões acadêmicas, essa teoria nos faz acreditar, a ter esperança de que se possa mudar a formação que temos. No entanto, sabemos que não é suficiente; não podemos acreditar que essa teoria ou outra irá mudar radicalmente a educação, que esse abismo entre teoria e pratica terminará, ou que a partir de tal teoria se estará formando homens conscientes, críticos em seu contexto.

A maneira como a situação está se desenhando leva a crer que apesar, de várias teorias sobre formação já serem bem trabalhadas nas universidades, de terem grupos de estudos e discussões sobre tais temas, o que ocorre na realidade da escola é o inverso, há um abismo entre teoria e prática, ou seja, há uma enorme distância entre a universidade e a escola. O que percebemos é uma educação tradicional, na qual o único objetivo é uma vaga na universidade, que não tem o objetivo de formar pessoas críticas, conscientes e emancipadas, mas sim verdadeiro robôs aptos à reprodução de conteúdos.

Por isso questionamos: será que é essa a formação que queremos? Uma sociedade com pessoas acríticas, robotizadas, passivas? Por isso precisamos mais do que novas teorias, é preciso uma reflexão mais profunda e uma ação mais efetiva.

Por fim, reiteramos nossos questionamentos, no intuito de achar alguma resposta sobre essa formação. Talvez seja valido refletir como as políticas educacionais chegam à escola e 
impõem leis, normas e mudanças. A outra questão é relacionada à maneira como o currículo é imposto às escolas sem levar em consideração o seu contexto, camuflado de interesses da classe dominante. São questões a serem trabalhadas em estudos posteriores.

\section{REFERÊNCIAS}

CONTRERAS, José. A autonomia de professores. São Paulo: Cortez, 2002,

DEWEY, J. Como pensamos. Como se relaciona o pensamento reflexivo com o processo educativo: uma reexposição. São Paulo, $3^{\text {a }}$ Ed. Companhia Editora Nacional, 1959.

.Vida e educação;São Paulo, 10 " ed.,melhoramento: Fundação Nacional

de Material Escolar, 1978.

MARCHESI, Álvaro, MARTíN, Elena. Qualidade do ensino em tempos de mudança; Trad. Fátima Murad. Porto Alegre: Artmed, 2003.

PÉREZ GOMEZ, A. O pensamento prático do professor - A formação do professor como profissional reflexivo. In: NÓVOA, A. (coord.). Os professores e sua formação. $2^{\mathrm{a}}$ ed. Lisboa: Dom Quixote, 1992.

PIMENTA, S. G., ANASTASIOU, Lea Camargo. Docência no ensino superior. São Paulo: Cortez, 2002. (ColeçSo Docência em Formação)

SCHÖN, D. Formar Professores como profissionais reflexivos. In: NÓVOA, A. (Coord.). Os professores e sua formação. $2^{\mathrm{a}}$ ed. Lisboa: Dom Quixote, 1992.

.Educando o profissional reflexivo: um novo design para o ensino e a aprendizagem. Porto Alegre, Artmed, 2000.

TARDIF, Maurice. Saberes docentes e formação profissional. Trad. Francisco Pereira. Petrópolis, RJ: Vozes, 2002.

VÁSQUEZ, Adolfo S. Filosofia da práxis. Rio de Janeiro, paz e Terra, 1977.

ZEICHNER, K. M. Novos caminhos para o practicum: uma perspectiva para os anos90. In: NÓVOA, A. (Coord.). Os professores e sua formação. $2^{\text {a }}$ ed. Lisboa: Dom Quixote, 1992.

A formação reflexiva de professores: idéias e práticas. Lisboa: Educa, 1993. 